\title{
Lithopedion Causing Intestinal Obstruction in a 71-Year-Old Woman: A Case Report
}

\section{Litopedia causando obstrução intestinal em idosa de 71 anos: relato de caso}

\author{
Francisco Eliomar Gomes de Oliveira ${ }^{1}$ Sandra Regina Alves dos Santos ${ }^{2}$ Bruno Gomes Duarte ${ }^{2}$ \\ Alexandre Sabino Sisnando ${ }^{3}$ ()
}

${ }^{1}$ Board of Directors, Hospital de Aeronáutica de Recife, Força Aérea Brasileira, Jaboatão dos Guararapes, PE, Brazil

${ }^{2}$ Division of Medicine, Hospital Central de Aeronáutica, Força Aérea Brasileira, Rio de Janeiro, RJ, Brazil

3 Division of Medicine, Fortaleza Health Squadron, Força Aérea

Brasileira, Fortaleza, CE, Brazil

Rev Bras Ginecol Obstet 2019;41:129-132.
Address for correspondence Alexandre Sabino Sisnando, ESP, Av. Rui Barbosa 1032, bloco A, apt 201, 60115-221 Fortaleza, CE, Brazil

(e-mail: alexsisnando@yahoo.com.br).

\section{Abstract \\ Keywords \\ - lithopedion \\ - stone baby \\ - ectopic pregnancy \\ - abdominal pregnancy \\ - extrauterine pregnancy}

\section{Resumo}

\section{Palavras-chave}

- litopedia

- bebê de pedra

- gravidez ectópica

- gravidez abdominal

- gravidez extrauterina
Ectopic pregnancy is the leading cause of pregnancy-related death during the first trimester, and it occurs in 1 to $2 \%$ of pregnancies. Over $90 \%$ of ectopic pregnancies are located in the fallopian tube. Abdominal pregnancy refers to an ectopic pregnancy that has implanted in the peritoneal cavity, external to the uterine cavity and fallopian tubes. The estimated incidence is 1 per 10,000 births and $1.4 \%$ of ectopic pregnancies. Lithopedion is a rare type of ectopic pregnancy, and it occurs when the fetus from an unrecognized abdominal pregnancy may die and calcify. The resulting "stone baby" may not be detected for decades and may cause a variety of complications. Lithopedion is a very rare event that occurs in $0.0054 \%$ of all gestations. About 1.5 to $1.8 \%$ of the abdominal babies develop into lithopedion. There are only $\sim 330$ known cases of lithopedion in the world. We describe a lithopedion that complicated as intestinal obstruction in a 71-year-old woman.

A gravidez ectópica é a principal causa de morte materna no primeiro trimestre, e ocorre em 1 a $2 \%$ das gestações. Mais de $90 \%$ ocorrem nas tubas uterinas. Gravidez abdominal refere-se à gravidez ectópica implantada na cavidade peritoneal, externamente ao útero e às tubas uterinas. A incidência estimada é de 1 por 10 mil nascimentose $1,4 \%$ das gravidezes ectópicas. A litopedia é um tipo raro de gravidez ectópica, e ocorre quando o feto de uma gravidez abdominal não reconhecida morre e se calcifica. O "bebê de pedra" resultante pode não ser detectado por décadas, e pode causar complicações futuras. A litopedia é um evento muito raro que ocorre em $0,0054 \%$ de todas as gestações. Cerca de 1,5 a 1,8\% dos bebês abdominais se tornam litopédios. Existem somente cerca de 330 casos conhecidos de litopedia no mundo. Descrevemos uma litopedia que se agravou, tornando-se uma obstrução intestinal, em uma idosa de 71 anos.

(1) Alexandre Sabino Sisnando's ORCID is https://orcid.org/0000-

0002-2529-1479.

received

July 22, 2018

accepted

October 1, 2018
DOI https://doi.org/

$10.1055 / \mathrm{s}-0038-1676060$. ISSN 0100-7203.
Copyright @ 2019 by Thieme Revinter Publicações Ltda, Rio de Janeiro, Brazil
License terms

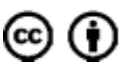




\section{Introduction}

Ectopic pregnancy is the leading cause of pregnancy-related death during the first trimester, and it is estimated to occur in 1 to $2 \%$ of pregnancies. Women who have one ectopic pregnancy are at increased risk for another such pregnancy and for future infertility. ${ }^{1}$ Over $90 \%$ are located in the fallopian tube (interstitial: $2.4 \%$; isthmic: $12.0 \%$; ampullary: $70.0 \%$; and fimbrial: $11.1 \%)$, while the remainder get implanted in locations such as the abdomen (1.3\%), the ovaries (3.2\%), cesarean scars (hysterotomy), and the cervix. ${ }^{2}$ Abdominal pregnancy refers to a pregnancy that has implanted in the peritoneal cavity, external to the uterine cavity and fallopian tubes. The estimated incidence is 1 per 10,000 births and $1.4 \%$ of ectopic pregnancies. ${ }^{3}$ There are reports of abdominal pregnancies occurring after hysterectomy. ${ }^{4,5}$ Rarely, the fetus from an unrecognized abdominal pregnancy may die and calcify. The resulting lithopedion ("stone baby") may not be detected for decades, and may cause a variety of complications (intra- abdominal abscesses, adhesions, masses, or fistulas). In most cases, the lithopedion can be identified on a simple abdominal $\mathrm{x}$-ray of the abdomen, often as an incidental finding. ${ }^{6}$ Given the rarity of implantation at these sites, much of the information surrounding the diagnosis and treatment of these pregnancies has been derived from small observational studies and case reports. This makes it so important to publish cases of ectopic pregnancies, especially in such unusual presentations, so we may improve the optimal approach to their evaluation and management, since it has been difficult to determine.

\section{Case Report}

We report the case of an elderly woman who was admitted to the emergency room of a tertiary military hospital in the city of Rio de Janeiro, Brazil, with clinical symptoms of intestinal obstruction. A 71-year-old woman, white, widowed, a retired telephone operator, who was born and living in Rio de Janeiro, sought emergency care complaining of abdominal pain in the hypogastric region and vomiting that had begun two days earlier. She evolved with anorexia, abdominal distension, a cessation of flatus and bowel movements, and fecal vomiting. She denied having had a fever before admission to the emergency room. As pathological antecedents, she had systemic arterial hypertension, which was controlled with regular use of medications. The patient underwent a reduction mammoplasty at the age of 31 , without other surgeries or comorbidities, and denied having any allergies. She had her menarche at age 14, and menopause at 65 , with regular cycles, and was G5P1A3, with a gestation at 18 years of age completed with vaginal delivery. The patient had 3 induced abortions, the last one at age 40 . At 60 years of age, upon routine transvaginal ultrasonography, a retained mummified fetus (abdominal pregnancy) was diagnosed, and she was referred for surgical excision but did not accept it, because she was completely asymptomatic.

Upon admission, the patient was alert, aware f time and space, with regular general condition, dehydrated $(2+/ 4)$, and with normal skin color. She had arrhythmia, but a normal heart rate, and a blood pressure of $200 \times 100 \mathrm{mmHg}$. The patient was eupneic, and had normal respiratory auscultation. The abdomen was globose, flaccid, hypertympanic at percussion, and with weak peristalsis, with no signs of peritoneal irritation, but discretely painful to superficial and deep palpation. There was a palpable mass measuring $\sim 20 \mathrm{~cm}$ in its largest diameter, of hardened consistency and irregular contours, adhered to deep planes, in the hypogastric region. There were no ascites or collateral circulation. The rectal touch showed hardened stools in the rectal ampulla, with no blood stains on the glove. The extremities of the patient exhibited no abnormalities.

Upon radiography, the acute abdomen routine showed a $20-\times-15-\mathrm{cm}$ radiopaque image with organized bone density in the hypogastrium (-Fig. 1). There was also significant distension of loops and air-fluid levels.

The abdominal ultrasonography showed an image compatible with the retained fetus. In addition, a computed tomography scan was suggestive of mesenteric ischemia. In the emergency room, $\sim 700 \mathrm{~mL}$ of fecal fluid contents were removed through a nasogastric tube, with concomitant volume replacement and analgesia. After the diagnosis of intestinal obstruction, the patient underwent an exploratory laparotomy six hours after hospital admission. The surgical inventory of the cavity confirmed the presence of a mummified fetus in the pelvis (-Fig. 2), as well as adherences of the pelvis at 60 and $80 \mathrm{~cm}$ from the ileocecal valve and, at $10 \mathrm{~cm}$ from this location, an adherence between the ilium and the fetus. The small intestine loops were distended, with violet color and without signs of

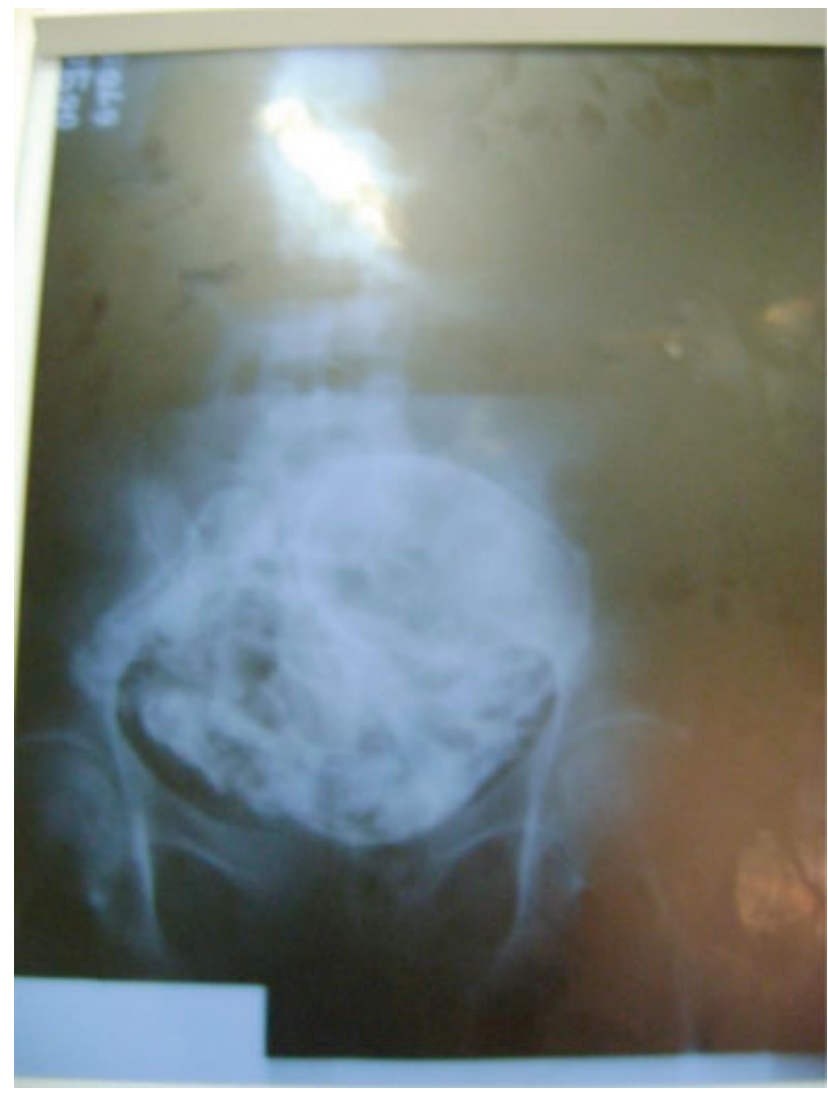

Fig. 1 Abdominal radiography showing a $20-x-15-\mathrm{cm}$ radiopaque image with organized bone density in the hypogastrium and, in addition, significant distension of the loops and air-fluid levels. 


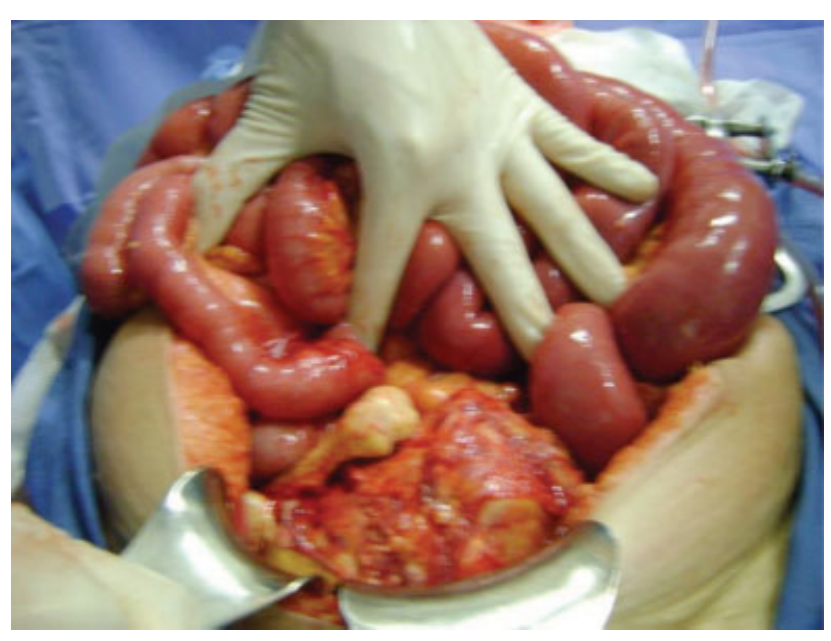

Fig. 2 Intraoperative view of the abdominal cavity showing the mass, including visible bone structures, compatible with a mummified fetus (lithopedion) in the pelvis.

ischemia; the mesenteric vessels were palpable. The liver, the gallbladder and the common bile duct did not present any macroscopic alterations. The uterus and right fallopian tube were identified as being intact, without visualization of the left tube after surgical excision of the fetus. A lysis of adhesions, dissection and resection of the mummified fetus was performed, without complications, during the surgery. By the analysis of the weight and size of the piece, along with the radiography performed, the fetus was compatible with a term gestation ( - Fig. 3 ). The patient remained in the intensive care unit during the first three postoperative days, breathing in ambient air. She presented right pneumothorax after deep vein puncture, which was drained in water seal for four days. She developed satisfactory results, being discharged eight days after surgery.

\section{Discussion}

Atrash et $\mathrm{al}^{3}$ demonstrated, from an analysis of 11 abdominal pregnancy-related deaths and an estimated 5,221 abdominal

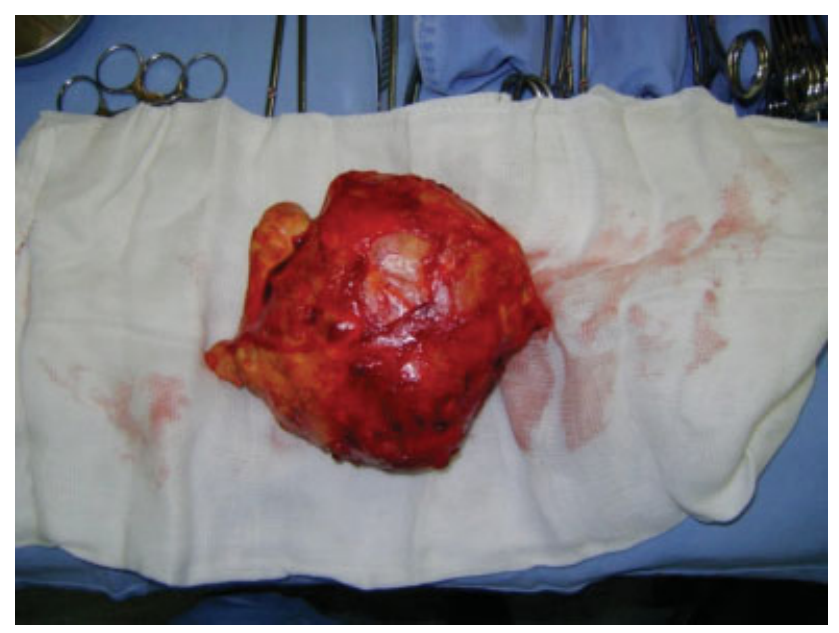

Fig. 3 Surgical specimen compatible with a "stone baby," the product of a term abdominal gestation. pregnancies in the United States, that there were 10.9 abdominal pregnancies per 100,000 live births, and 9.2 abdominal pregnancies per 1,000 ectopic pregnancies. The mortality rate was 5.1 per 1,000 cases of abdominal pregnancies. Only 1 out of 9 women who reached the hospital alive had an accurate preoperative diagnosis of abdominal pregnancy, which suggests that preventing abdominal pregnancy-related death may depend, at least in part, on increasing the awareness of physician awareness regarding its clinical features. ${ }^{3}$

The potential sites of abdominal pregnancy include the omentum, the pelvic sidewall,the broad the ligament, posterior cul-de-sac, the abdominal organs (the spleen, the bowel, the liver, for example), large pelvic vessels, the diaphragm, and the uterine serosa. ${ }^{7-12}$

It is not known whether abdominal pregnancies are a result of secondary implantation from an aborted tubal pregnancy or the result of intraabdominal fertilization, with primary implantation in the abdomen. ${ }^{7,8}$ The risk factors for abdominal pregnancy include tubal damage, pelvic inflammatory disease, endometriosis, assisted reproductive techniques, and multiparity. ${ }^{10,13}$

Because of the variable location in the abdomen, abdominal pregnancy is associated with a wide range of signs and symptoms. In contrast to tubal ectopic pregnancies, abdominal pregnancies may go undetected until an advanced gestational age; some pregnancies go all the way to term. In such cases, the fetal movements can be detected and may be painful, and the fetus may assume an unusual lie. When the pregnancy implants in the bowel, nausea and vomiting may be prominent symptoms. Vaginal bleeding is less frequent than in tubal ectopic pregnancies; however, vaginal bleeding may occur, since the endometrium still responds to changes in pregnancy hormones. ${ }^{14}$ Some women present with an acute abdomen and shock due to severe intra-abdominal hemorrhage from placental separation or rupture of maternal blood vessels or viscera. Bowel obstruction and formation of fistulae are other rare presentations. ${ }^{3,14,15}$ In rare cases, the pregnancy may be diagnosed after a failed induction due to lack of myometrial response to oxytocin stimulation. ${ }^{16}$

In order to make the diagnosis, all women of reproductive age with abdominal pain, vaginal bleeding, or menstrual abnormalities should be tested for pregnancy. Once pregnancy is established, the location of the pregnancy (intrauterine or extrauterine) is typically made by ultrasound examination. A high index of suspicion is important to establish a diagnosis of abdominal pregnancy. The classic ultrasound finding is the absence of myometrial tissue between the maternal bladder and the placenta. ${ }^{8,14}$ An empty uterus may be visualized. Other findings suggestive of the diagnosis include poor definition of the placenta, oligohydramnios, and unusual fetal lie. ${ }^{14}$

An advanced abdominal gestation may be misinterpreted as being intrauterine if the ultrasonographer does not evaluate the myometrium during the examination. Computed tomography and magnetic resonance imaging scans can be useful to confirm the diagnosis, distinguish anatomic relationships and potential vascular connections, and assess placental adherence. The differential diagnosis includes ectopic pregnancy in other locations, intrauterine pregnancy 
in a rudimentary uterine horn, abruptio placenta, and uterine rupture. $^{17}$

Abdominal pregnancies, even when advanced, are interrupted at diagnosis, as the potential for delivery of a healthy infant is poor, and the risk of maternal complications is high. If the diagnosis is made late in the pregnancy, a viable infant may be delivered via laparotomy. Expectant management to gain fetal maturity has been attempted, and has been successful in a few cases. ${ }^{21}$ Abdominal gestation implies a high incidence of fetal deformations and mortality, as well as maternal mortality. ${ }^{22}$

The mainstay of the treatment for advanced abdominal pregnancy is surgery, but the optimal approach has not yet been determined. The fetus can be delivered easily; the key issue is how to manage the placenta. In this case, as it was a mummified fetus, there were no concerns regarding the placenta or risk of bleeding related to it.

This type of ectopic pregnancy is very rare, and it occurs when the fetus from an unrecognized abdominal pregnancy maybe dies and calcifies. The resulting lithopedion ("stone baby") may not be detected for decades, and may cause a variety of complications (intra-abdominal abscess, adhesions, masses, or fistulas). Lithopedion is a rare event that occurs in $0.0054 \%$ of all gestations. About 1.5 to $1.8 \%$ of the abdominal babies develop into lithopedion. There are only $\sim 330$ known cases of "stone babies" in the world. ${ }^{23}$

In most cases, the lithopedion can be identified on a simple x-ray or on an ultrasound of the abdomen, often as an incidental finding. What makes this case more interesting is that the patient knew that she carried a mummified fetus and had probably been warned about the risks. In this case, emergency surgery was performed due to intestinal obstruction as a resultant complication.

Conflict of Interests

The authors have none to declare.

\section{References}

1 Centers for Disease Control and Prevention (CDC). Ectopic pregnancy-United States, 1990-1992. MMWR Morb Mortal Wkly Rep 1995;44(03):46-48

2 Bouyer J, Coste J, Fernandez H, Pouly JL, Job-Spira N. Sites of ectopic pregnancy: a 10 year population-based study of 1800 cases. Hum Reprod 2002;17(12):3224-3230

3 Atrash HK, Friede A, Hogue CJ. Abdominal pregnancy in the United States: frequency and maternal mortality. Obstet Gynecol 1987; 69(3 Pt 1):333-337
4 Binder DS. Thirteen-week abdominal pregnancy after hysterectomy. J Emerg Med 2003;25(02):159-161

5 Fader AN, Mansuria S, Guido RS, Wiesenfeld HC. A 14-week abdominal pregnancy after total abdominal hysterectomy. Obstet Gynecol 2007;109(2 Pt2):519-521

6 Odom SR, Gemer M, Muyco AP. Lithopedion presenting as intraabdominal abscess and fecal fistula: report of a case and review of the literature. Am Surg 2006;72(01):77-78

7 Dover RW, Powell MC. Management of a primary abdominal pregnancy. Am J Obstet Gynecol 1995;172(05):1603-1604

8 Varma R, Mascarenhas L, James D. Successful outcome of advanced abdominal pregnancy with exclusive omental insertion. Ultrasound Obstet Gynecol 2003;21(02):192-194

9 Onan MA, Turp AB, Saltik A, Akyurek N, Taskiran C, Himmetoglu O. Primary omental pregnancy: case report. Hum Reprod 2005;20 (03):807-809

10 Ludwig M, Kaisi M, Bauer O, Diedrich K. The forgotten child-a case of heterotopic, intra-abdominal and intrauterine pregnancy carried to term. Hum Reprod 1999;14(05):1372-1374

11 Shippey SH, Bhoola SM, Royek AB, Long ME. Diagnosis and management of hepatic ectopic pregnancy. Obstet Gynecol 2007;109(2 Pt2):544-546

12 Phupong V, Tekasakul P, Kankaew K. Broad ligament twin pregnancy. A case report. J Reprod Med 2001;46(02):144-146

13 Tsudo T, Harada T, Yoshioka H, Terakawa N. Laparoscopic management of early primary abdominal pregnancy. Obstet Gynecol 1997;90(4 Pt 2):687-688

14 Rahman MS, Al-Suleiman SA, Rahman J, Al-Sibai MH. Advanced abdominal pregnancy-observations in 10 cases. Obstet Gynecol 1982;59(03):366-372

15 Cormio G, Santamato S, Vimercati A, Selvaggi L. Primary splenic pregnancy. A case report. J Reprod Med 2003;48(06):479-481

16 Lamina MA, Akinyemi BO, Fakoya TA, Shorunmu TO, Oladapo OT. Abdominal pregnancy: a cause of failed induction of labour. Niger J Med 2005;14(02):213-217

17 Kitade M, Takeuchi H, Kikuchi I, Shimanuki H, Kumakiri J, Kinoshita K. A case of simultaneous tubal-splenic pregnancy after assisted reproductive technology. Fertil Steril 2005;83(04):1042

18 Jazayeri A, Davis TA, Contreras DN. Diagnosis and management of abdominal pregnancy. A case report. J Reprod Med 2002;47(12): 1047-1049

19 Rahaman J, Berkowitz R, Mitty H, Gaddipati S, Brown B, Nezhat F. Minimally invasive management of an advanced abdominal pregnancy. Obstet Gynecol 2004;103(5 Pt 2):1064-1068

20 Lockhat F, Corr P, Ramphal S, Moodley J. The value of magnetic resonance imaging in the diagnosis and management of extrauterine abdominal pregnancy. Clin Radiol 2006;61(03):264-269

21 Beddock R, Naepels P, Gondry C, et al. [Diagnosis and current concepts of management of advanced abdominal pregnancy]. Gynécol Obstét Fertil 2004;32(01):55-61

22 Stevens CA. Malformations and deformations in abdominal pregnancy. Am J Med Genet 1993;47(08):1189-1195

23 Gedam BS, Shah Y, Deshmukh S, Bansod PY. Skeletal remains of mummified foetus for 36 years in mother's abdomen. Int J Surg Case Rep 2015;7C:109-111 